\title{
Factors That May Affect Delayed Relief Of Trigeminal Neuralgia After Microneurosurgery And The Long-Term Outcomes Associated With Delayed Relief
}

This article was published in the following Dove Press journal:

Journal of Pain Research

\author{
Zhu Deng ${ }^{1,2, *}$ \\ Ruiquan Liu ${ }^{1,2, *}$ \\ Yin Liu ${ }^{2,3}$ \\ Zheng Wang ${ }^{2,3}$ \\ Yanbing $\mathrm{Yu}^{1,2}$ \\ Li Zhang $\mathbb{D}^{1,2}$
}

'Graduate School of Peking Union Medical College, Chinese Academy of Medical Sciences, Beijing, People's Republic of China; ${ }^{2}$ Department of Neurosurgery, China-Japan Friendship Hospital, Beijing, People's Republic of China; ${ }^{3}$ Peking University Health Science Center, Beijing, People's Republic of China

*These authors contributed equally to this work
Correspondence: Li Zhang

Department of Neurosurgery,

China-Japan Friendship Hospital, No. 2

Yinghua Dongjie, Hepingli, Chaoyang

District, Beijing, People's Republic of

China

Tel +8618910586699

Fax +86-10-64217749

Email allan18910586699@163.com
Objective: Microvascular decompression (MVD) combined with partial sensory rhizotomy (PSR) with the retrosigmoid approach has become the most effective surgical treatment for trigeminal neuralgia $(\mathrm{TN})$. There is variability in the pain relief processes observed in postoperative patients. The purpose of this study was to investigate delayed relief (DR) and its predictors after MVD and/or PSR for the treatment of TN and study the long-term effects associated with DR.

Methods: Patients with primary TN who underwent MVD and/or PSR by the same surgeon at the China-Japan Friendship Hospital from March 2009 to December 2017 were included in the study, and all patients were followed for at least 1 year after the operation. DR was defined as follows: no changes in the Barrow Neurological Institute (BNI) score on the third day after surgery and a BNI score of I-II in the absence of any medication after a period of pain. Preoperative, intraoperative and postoperative differences were compared between the DR and non-DR groups, and the relationships between the various factors and DR was analyzed.

Results: A total of 105 patients, including 20 patients with DR (19\%), 78 patients with nonDR (74\%), and 7 patients without relief, were included in this study. The follow-up period ranged from 13 months to 118 months (average, 5.39 years/65 months). The duration of postoperative pain in the DR group was 3-365 days, with an average of 108 days. Statistical analysis found that no factor predicted the occurrence of DR, and the occurrence of postoperative DR did not affect the long-term effects observed in patients.

Conclusion: DR did not affect the long-term effects after MVD and/or PSR. Therefore, it is recommended that patients should be monitored for approximately 3 months after MVD and/ or PSR and then evaluated for surgical effects. No reoperations should be performed immediately.

Keywords: microvascular decompression, partial sensory rhizotomy, trigeminal neuralgia, delayed relief

\section{Introduction}

Trigeminal neuralgia (TN) is a common chronic cranial neurological disease with an annual incidence of approximately $12.6-27 / 100,000 .{ }^{1} \mathrm{TN}$ manifests as recurrent, unilateral, stimulation-induced, shock-like, paroxysmal pain that is localized in the trigeminal innervation area. TN can be classified into two types: classical TN and secondary TN, with classical TN always caused by neurovascular conflict (NVC). ${ }^{2,3}$ 
In patients with primary $\mathrm{TN}$, drug therapy (such as carbamazepine) can be used first, with surgical treatment considered when the side-effects of drugs are intolerable or the drugs produce poor efficacy. ${ }^{4}$ Regarding the surgical treatment of TN, Jannetta pioneered microvascular decompression (MVD) based on the vascular compression theory proposed by Dandy. ${ }^{5}$ Patients in whom intraoperative exploration did not reveal any vascular compression of the trigeminal nerve root or who are suspected of having multiple sclerosis (MS) can be treated with partial sensory rhizotomy (PSR). ${ }^{6,7}$ Imaging is necessary before choosing which surgical procedure to perform. Magnetic resonance imaging (MRI) is routinely used in the preoperative examination of TN. Patients with obvious NVC on MRI can be treated with MVD. ${ }^{8}$

Patients with TN present a certain amount of variability in the pain relief processes reported after MVD and/or PSR: most patients experience immediate postoperative pain relief, some patients experience delayed relief (DR), and a small number of patients experience no relief. In terms of long-term efficacy, some patients present post-

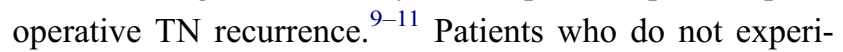
ence pain relief after surgery may have to undergo reoperation. However, the difficulty and risk of reoperation are significantly higher in $\mathrm{TN}$ patients who present no relief or recurrence after the first MVD and/or PSR. ${ }^{12}$ Since some patients have DR after MVD and/or PSR, patients who do not exhibit immediate relief after surgery should not be considered for immediate reoperation. However, nearly no studies have reported on DR in TN patients who underwent MVD and/or PSR.

We collected initial and postoperative follow-up data in TN patients who underwent MVD and/or PSR in our hospital from March 2009 to December 2017. The purpose of this retrospective study was to obtain data on the incidence and duration of DR, to explore the factors that may cause DR and to determine whether DR affects long-term effects in TN patients. Therefore, this study provides useful information that may allow reoperation to be avoided in TN patients whose pain is not alleviated immediately after MVD and/or PSR.

\section{Methods}

\section{Objectives Of The Study}

The subjects in this study were primary TN patients who underwent MVD and/or PSR in the neurosurgery department of the China-Japan Friendship Hospital from March
2009 to December 2017. We excluded patients with secondary TN (such as TN secondary to intracranial tumors), patients with MS, patients who underwent MVD reoperations, patients who were lost to follow-up, patients who had a follow-up time $<1$ year, patients who had incomplete clinical data, and patients who had other neurological diseases (such as facial spasms, glossopharyngeal neuralgia, etc.). The study was approved by the Ethics Committee of the China-Japan Friendship Hospital and all patients who participated in the study signed informed consent.

\section{Data Collection And Outcome Assessment}

The demographic and clinical characteristics of the patients, including sex, age ( $<60$ or $\geq 60$ years old), pain side, pain duration, trigeminal nerve branch involvement, pain type (typical or atypical), previous trigeminal sensory root destruction treatment, and the initial treatment effect of carbamazepine, were collected and recorded. The specific intraoperative conditions of the patients, including surgical methods (simple MVD, simple PSR or MVD + PSR), posterior fossa volume (intraoperative findings, such as platybasia or basilar impression, which were considered narrow posterior fossa volume), arachnoid thickening adhesion (arachnoid thickening was defined as arachnoid opaque or ground-glass changes, while arachnoid adhesions were considered if the arachnoid formed an adhesion between the trigeminal nerve and the blood vessels and brain tissue), type of responsible vessel formation, and decompression (adequate decompression) were recorded. All patients completed follow-up interviews by independent observers through telephone calls or outpatient visits. The data collected during follow-up included the presence and duration of DR and the recovery of postoperative patients (with or without recurrence). All patients were followed up for more than 1 year.

To evaluate the level of postoperative pain in $\mathrm{TN}$ patients, we used the Barrow Neurological Institute ${ }^{13}$ (BNI) pain scale score (Table 1). The postoperative outcomes were used to divide the patients into two groups: those with good results (BNI scores I-II) and those with poor results (BNI scores III-V). The patients' long-term postoperative effects were assessed at the last follow-up. We defined DR as follows: no significant change in the BNI score on the third day after surgery compared with the 
Table I Barrow Neurological Institute (BNI) Pain Scores

\begin{tabular}{|l|l|}
\hline Score & Description \\
\hline I & No pain, no medication \\
II & Occasional pain, not requiring medication \\
III & Some pain, adequately controlled with medication \\
IV & Some pain, not adequately controlled with medication \\
V & Severe pain/no pain relief \\
\hline
\end{tabular}

score before surgery and a BNI score of I-II in the absence of any medication after a period of pain.

\section{Therapeutic Method}

The surgical methods were selected on the basis of the following basic principles: (1) preoperative MRI evaluation of patients with significant NVC and a willingness to undergo MVD, (2) patients who were unwilling to accept postoperative facial numbness with an intraoperative finding of obvious compression of the responsible vessels on the trigeminal nerve root (sensory root displacement or pressure trace) who were treated with MVD alone, (3) patients in whom MVD+PSR was recommended or who were unable to achieve adequate decompression intraoperatively when the offending vessels were only slightly compressed or in contact with or near the trigeminal nerve roots or when the responsible vessels were in elderly patients (age $\geq 60$ years old) with single veins; and (4) if the intraoperative exploration did not reveal the responsible vessels, a simple PSR was performed. Patients were informed of the advantages and disadvantages of the various surgical methods preoperatively, and the surgical method was determined according to the patient's wishes and intraoperative exploration.

\section{Operative Technique}

All patients underwent surgery under general anesthesia and were placed in a lateral position with the affected side upward. We used a retrosigmoid approach and incised the skin, subcutaneous tissue, muscle and fascia. We drilled holes into the skull and enlarged the diameter of the holes to approximately $2 \mathrm{~cm}$. The dura mater and tissue suspended under the skin was opened, and we gently manipulated the cerebellar hemisphere, aspirated some of the cerebrospinal fluid, and entered the cerebellopontine angle (CPA). We carefully dissected the arachnoid membrane around the trigeminal nerve root. The position of the patient's head and the angle of the microscope were adjusted, and the sensory roots of the trigeminal nerve were carefully explored to clarify the compression of the responsible vessels on the nerves. Different surgical methods were adopted according to the preoperative willingness of the patient and the specific conditions observed during the intraoperative exploration. For patients who were treated with MVD alone, the responsible vessel was dissected and moved away from the nerve root, and a piece of Teflon felt was inserted between the vessel and the brainstem. For patients treated with MVD+PSR, the MVD was first completed in accordance with the above surgical method, and then $1 / 3-2 / 3$ of the trigeminal nerve sensory root was removed according to the level of preoperative pain involving the trigeminal nerve branch (in patients whose pain range was in the third branch of the trigeminal nerve, $1 / 3$ to $1 / 2$ was removed, while in patients whose pain range was in the second or the second and third branches of the trigeminal nerve, $2 / 3$ was removed). Finally, once hemostasis was achieved, we sutured the dura mater, repaired the skull defect with a titanium plate, and sutured the muscles and skin.

\section{Statistical Analyses}

All statistical analyses were performed using SPSS version 24.0 (IBM, Armonk, New York, USA). All analyses were performed for only the DR group and the non-DR group. The mean \pm standard deviation (SD) is used to represent continuous variables, such as the duration of the pain. Kolmogorov-Smirnov tests were applied to test for the normality of continuous variables, and a independent sample $t$-test was used to compare the two groups; comparisons of categorical variables were performed with Pearson's $\chi^{2}$ test or Fisher's exact test. Long-term postoperative effects were compared with a Kaplan-Meier analysis. Relevant factors that may have affected the occurrence of DR in the statistical analyses included sex, age, pain side, pain duration, trigeminal nerve branch involvement, pain type, previous trigeminal sensory root destruction treatment, initial treatment effect of carbamazepine, posterior fossa volume, arachnoid thickening adhesion, responsible vessel formation type, and decompression. Logistic regression was used for the multivariate analysis to further evaluate the correlations between various factors and DR. The strength of the association was evaluated with odds ratios (ORs) and $95 \%$ confidence intervals (CIs). Factors with $\mathrm{P}<0.2$ in the univariate analysis were included in the multivariate analysis. In addition, considering the long-term efficacy of TN after MVD, we included only venous compression in 
the multifactor analysis. A P value $\leq 0.05$ indicated that the difference was statistically significant.

\section{Results}

\section{Demographic Data And Clinical Characteristics}

A total of $181 \mathrm{TN}$ patients underwent microneurosurgery with a retrosigmoid approach by the same neurosurgeon in the neurosurgery department of the China-Japan Friendship Hospital from March 2009 to December 2017. Among these patients, 12 (6.6\%) had secondary TN, 20 (11\%) had other neurological diseases, and $44(24.3 \%)$ were followed for less than 1 year. After the above 76 patients were excluded, 105 patients were finally included in this study, including 20 (19\%) who were included in the DR group, 78 (74\%) who were included in the non-DR group, and $7(7 \%)$ who experienced pain until the end of follow-up. Table 2 shows the duration of postoperative pain, follow-up period and postoperative recurrence time in the DR patients.

Table 3 shows the demographic data and clinical characteristics of the patients. The data showed that there was no statistically significant difference in sex, age $(<60$ or $\geq 60$ years old), pain side, pain duration, trigeminal nerve

Table 2 The Duration Of Postoperative Pain, Follow-Up Period And Postoperative Recurrence Time In The DR Group

\begin{tabular}{|l|l|l|l|}
\hline Number & $\begin{array}{l}\text { Follow-Up } \\
\text { Period } \\
\text { (Months) }\end{array}$ & $\begin{array}{l}\text { Duration Of } \\
\text { Postoperative } \\
\text { Pain (Days) }\end{array}$ & $\begin{array}{l}\text { Recurrence } \\
\text { (Months) }\end{array}$ \\
\hline 1 & 118 & 10 & \\
2 & 118 & 7 & \\
3 & 106 & 365 & \\
4 & 100 & 365 & 50 \\
5 & 93 & 4 & 60 \\
6 & 87 & 7 & \\
7 & 82 & 7 & \\
8 & 73 & 60 & 20 \\
9 & 70 & 7 & \\
10 & 68 & 181 & \\
11 & 68 & 183 & \\
12 & 64 & 160 & \\
13 & 63 & 50 & \\
14 & 51 & 80 & \\
15 & 39 & 90 & \\
16 & 37 & 3 & \\
17 & 30 & 110 & \\
18 & 28 & 90 & \\
19 & 16 & 155 & \\
20 & 15 & & \\
\hline
\end{tabular}

Table 3 Demographic And Clinical Data Of The DR And NonDR Groups

\begin{tabular}{|c|c|c|c|}
\hline Variable & DR & Non-DR & $P$ value \\
\hline $\begin{array}{l}\text { Sex } \\
\qquad \text { Male } \\
\text { Female }\end{array}$ & $\begin{array}{l}4(20.0 \%) \\
16(80.0 \%)\end{array}$ & $\begin{array}{l}26(33.3 \%) \\
52(66.7 \%)\end{array}$ & $0.248^{\mathrm{a}}$ \\
\hline $\begin{array}{l}\text { Duration of pain, (years), mean } \\
\pm S D\end{array}$ & $6.7 \pm 5.2$ & $6.0 \pm 5.5$ & $0.831^{b}$ \\
\hline $\begin{array}{l}\text { Age (years), } \\
\quad<60 \\
\quad \geq 60\end{array}$ & $\begin{array}{l}\text { II (55.0\%) } \\
9(45.0 \%)\end{array}$ & $\begin{array}{l}39(50.0 \%) \\
39(50.0 \%)\end{array}$ & $0.690^{\mathrm{a}}$ \\
\hline $\begin{array}{l}\text { Side } \\
\text { Left } \\
\text { Right }\end{array}$ & $\begin{array}{l}9(45.0 \%) \\
\mathrm{II}(55.0 \%)\end{array}$ & $\begin{array}{l}32(41.0 \%) \\
46(59.0 \%)\end{array}$ & $0.748^{\mathrm{a}}$ \\
\hline $\begin{array}{l}\text { Distribution } \\
\text { VI } \\
\text { V2 } \\
\text { V3 } \\
\text { VI+V2 } \\
\text { V2+V3 } \\
\text { VI+V2+V3 }\end{array}$ & $\begin{array}{l}0(0 \%) \\
9(45.0 \%) \\
3(15.0 \%) \\
2(10.0 \%) \\
5(25.0 \%) \\
1(5 \%)\end{array}$ & $\begin{array}{l}0(0.0 \%) \\
24(30.8 \%) \\
9(11.5 \%) \\
12(15.4 \%) \\
27(34.6 \%) \\
6(7.7 \%)\end{array}$ & $0.727^{\mathrm{a}}$ \\
\hline $\begin{array}{l}\text { Carbamazepine } \\
\text { Effective } \\
\text { Invalid }\end{array}$ & $\begin{array}{l}\mathrm{II}(55.0 \%) \\
9(45.0 \%)\end{array}$ & $\begin{array}{l}49(62.8 \%) \\
29(37.2 \%)\end{array}$ & $0.522^{\mathrm{a}}$ \\
\hline $\begin{array}{l}\text { Type } \\
\text { Typical } \\
\text { Atypical }\end{array}$ & $\begin{array}{l}20(100 \%) \\
0(0 \%)\end{array}$ & $\begin{array}{l}74(94.9 \%) \\
4(5.1 \%)\end{array}$ & $0.301^{\mathrm{a}}$ \\
\hline $\begin{array}{l}\text { Destructive treatment } \\
\text { Yes } \\
\text { No }\end{array}$ & $\begin{array}{l}2(10.0 \%) \\
18(80.0 \%)\end{array}$ & $\begin{array}{l}9(11.5 \%) \\
69(88.5 \%)\end{array}$ & $0.846^{\mathrm{a}}$ \\
\hline
\end{tabular}

Notes: ${ }^{\mathrm{a}} \mathrm{P}$ value: Pearson's $\chi^{2}$ test or Fisher's exact test; ${ }^{\mathrm{b}} \mathrm{P}$ value: $t$-test.

branch involvement, pain type (typical or atypical), previous trigeminal sensory root destruction treatment, and the initial treatment effect of carbamazepine between the DR group and the non-DR group ( $\mathrm{P}>0.05)$. We also analyzed the demographic data and clinical characteristics in the MVD and MVD+PSR groups, and there was no statistically significant difference in these factors between the groups ( $\mathrm{P}>0.05$ and these $\mathrm{P}$ values are all greater than 0.2 ).

\section{Intraoperative Findings}

Table 4 shows the findings of intraoperative exploration and the treatments in the DR and non-DR groups. Intraoperative exploration revealed arachnoid adhesions in 19 cases (95.0\%) in the DR group and 78 cases in the non-DR group. A total of $61(78.2 \%)$ cases increased, but there was no statistically significant difference between the two groups 
Table 4 Intraoperative Findings And Treatments In The DR And Non-DR Groups

\begin{tabular}{|c|c|c|c|}
\hline Variable & DR & Non-DR & $P$ value \\
\hline $\begin{array}{l}\text { Posterior fossa volume } \\
\text { Normal } \\
\text { Narrow }\end{array}$ & $\begin{array}{l}9(45.0 \%) \\
\mathrm{II}(55.0 \%)\end{array}$ & $\begin{array}{l}34(43.6 \%) \\
44(56.4 \%)\end{array}$ & 0.910 \\
\hline $\begin{array}{l}\text { Arachnoid } \\
\text { Normal } \\
\text { Thickening or adhesion }\end{array}$ & $\begin{array}{l}\mathrm{I}(5.0 \%) \\
\mathrm{I}(9(95.0 \%)\end{array}$ & $\begin{array}{l}\mid 7(2 \mid .8 \%) \\
6 \mid(78.2 \%)\end{array}$ & 0.084 \\
\hline $\begin{array}{l}\text { Only venous compression } \\
\text { Yes } \\
\text { No }\end{array}$ & $\begin{array}{l}0(0.0 \%) \\
20(100.0 \%)\end{array}$ & $\begin{array}{l}6(7.7 \%) \\
72(92.3 \%)\end{array}$ & 0.200 \\
\hline $\begin{array}{l}\text { Double-artery compression } \\
\text { Yes } \\
\text { No }\end{array}$ & $\begin{array}{l}5(25.0 \%) \\
15(75.0 \%)\end{array}$ & $\begin{array}{l}6(7.7 \%) \\
72(92.3 \%)\end{array}$ & 0.029 \\
\hline $\begin{array}{l}\text { Method } \\
\text { MVD } \\
\text { PSR } \\
\text { MVD+PSR }\end{array}$ & $\begin{array}{l}9(45.0 \%) \\
0(0.0 \%) \\
I I(55.0 \%)\end{array}$ & $\begin{array}{l}27(34.6 \%) \\
4(5.1 \%) \\
47(60.3 \%)\end{array}$ & 0.457 \\
\hline $\begin{array}{l}\text { Decompression } \\
\text { Sufficient } \\
\text { Insufficient }\end{array}$ & $\begin{array}{l}17(85.0 \%) \\
3(15.0 \%)\end{array}$ & $\begin{array}{l}59(75.6 \%) \\
19(24.4 \%)\end{array}$ & 0.37 I \\
\hline
\end{tabular}

Notes: $\mathrm{P}$ value: Pearson's $\chi^{2}$ test or Fisher's exact test. Bold text represents significance.

$(\mathrm{P}>0.05)$. We also analyzed the effect of arachnoid thickening on long-term outcomes after MVD. We found that arachnoid thickening adhesions did not affect long-term outcomes $(\mathrm{P}=0.54)$. There were $5(25.0 \%)$ patients in the DR group and $6(7.7 \%)$ in the non-DR group with doubleartery compression, and the difference was significant $(\mathrm{P}=0.029)$. Patients with only venous compression accounted for $7.7 \%$ (6 cases) of patient in the non-DR group and no patients in the DR group. The responsible vessels in the DR group were predominantly the superior cerebellar artery (SCA) or the SCA combined with additional vascular compression. The responsible vessels in the DR group and the non-DR group are shown in Table 5. We also analyzed the findings of intraoperative exploration according to the MVD and MVD+PSR groups, and there was no statistically significant difference in these factors $(\mathrm{P}>0.05$, and all $\mathrm{P}$ values were greater than 0.2).

Among the univariate analyses of factors that may cause DR, only double-artery compression was significantly correlated with the occurrence of postoperative $\mathrm{DR}(\mathrm{P}=0.029)$ (Tables 3 and 4). In the univariate analysis, arachnoid adhesion thickening $(\mathrm{P}=0.084)$ was significant $(\mathrm{P}<0.2)$. Moreover, only venous compression $(\mathrm{P}=0.200)$
Table 5 Responsible Vessels In The DR And Non-DR Groups

\begin{tabular}{|l|l|l|}
\hline Responsible Vessels & DR & Non-DR \\
\hline SCA & $5(25.0 \%)$ & $18(23.1 \%)$ \\
AICA & $I(5.0 \%)$ & $8(10.3 \%)$ \\
PICA & $0(0.0 \%)$ & $I(1.3 \%)$ \\
BA & $I(5.0 \%)$ & $I(1.3 \%)$ \\
SPV & $0(0.0 \%)$ & $6(7.7 \%)$ \\
SCA+ AICA & $5(25.0 \%)$ & $5(6.4 \%)$ \\
SCA+ BA & $0(0.0 \%)$ & $I(1.3 \%)$ \\
SCA+ SPV & $5(25.0 \%)$ & $21(26.9 \%)$ \\
AICA+ SPV & $I(5.0 \%)$ & $7(9.0 \%)$ \\
BA+ SPV & $0(0.0 \%)$ & $I(1.3 \%)$ \\
SCA+ AICA+ SPV & $2(10.0 \%)$ & $4(5.1 \%)$ \\
AICA+ BA+ SPV & $0(0.0 \%)$ & $I(I .3 \%)$ \\
No vessel & $0(0.0 \%)$ & $4(4.1 \%)$ \\
\hline
\end{tabular}

Abbreviations: SCA, superior cerebellar artery; AICA, anterior inferior cerebellar artery; PICA, posterior inferior cerebellar artery; BA, basilar artery; SPV, superior petrosal vein.

was included in the logistic regression analysis. The results of the logistic regression analysis showed that there were no significant correlations between the occurrence of postoperative DR and double-artery compression $(\mathrm{P}=0.114)$, arachnoid adhesion thickening $(\mathrm{P}=0.141)$ and only venous compression $(\mathrm{P}=0.999)(\mathrm{P}>0.05)$.

\section{Long-Term Effects}

The average follow-up time of the 98 patients was 5.39 \pm 2.63 years (time range: $1.1-9.9$ years). The mean duration of pain in the postoperative DR group was 108 days (time range: 3 to 365 days). In our long-term follow-up, a total of $31(29.5 \%)$ patients reported recurrence; among these patients, a total of $4(20.0 \%)$ in the DR group and 27 $(34.6 \%)$ in the non-DR group reported recurrence. A Kaplan-Meier analysis was performed to compare longterm effects between the two groups (Figure 1), and there was no significant difference $(\mathrm{P}=0.202)$. We also analyzed the long-term effects according to the MVD and MVD + PSR groups and found no significant difference in the long-term effects of $\mathrm{TN}$ between the DR group and the non-DR group ( $\mathrm{P}=0.142)$. There was no significant difference in the long-term effects of TN between the DR group and the non-DR group according to whether MVD+PSR was performed $(\mathrm{P}=0.847)$.

\section{Discussion}

In this study, the incidence of postoperative DR was $19 \%$ in the $105 \mathrm{TN}$ patients who received MVD and/or PSR. Our comparative analysis of the long-term effects of the 


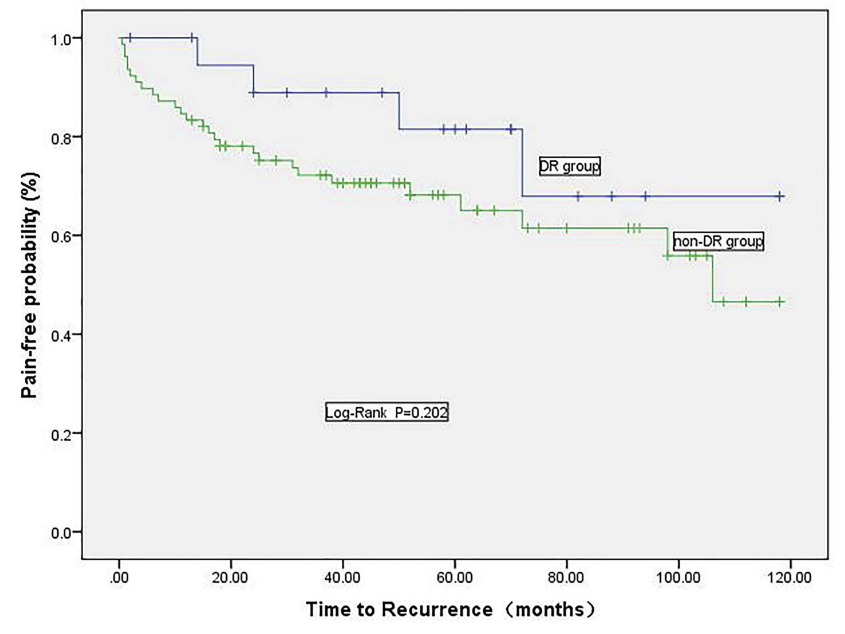

Figure I Kaplan-Meier survival curves for pain-free patients in the DR and non-DR groups.

DR and non-DR groups showed there was no significant difference between the two groups. In addition, no relevant factors were found to predict the occurrence of DR.

There was variability in the recovery process after MVD and/or PSR in patients with TN. Some postoperative patients experienced immediate pain relief, some experienced DR, some experienced no pain relief, and some experienced TN recurrence after initial pain relief. $^{6,10,14}$ Unlike facial spasm, postoperative DR is rare in patients with TN. Sindou et $\mathrm{al}^{14}$ found that $13 \%$ of $362 \mathrm{TN}$ patients who underwent MVD reported postoperative DR when they were followed up for a long time. Inoue et $\mathrm{al}^{10}$ evaluated long-term effects in 31 patients with TN caused by simple venous compression after MVD and found that DR appeared in 3 of these patients. In this study, the incidence of DR was not small in patients who underwent MVD and/or PSR. However, we found no correlation between the occurrence of DR and any factor.

Among TN patients who undergo MVD, the factors that may affect long-term effects are not currently very clear and may be related to the patient's age, sex and venous compression. ${ }^{15,16}$ Barker et $\mathrm{al}^{15}$ reported that patients with immediate postoperative pain relief after MVD often achieved better long-term effects than were observed in patients with postoperative DR. However, in our study, there was no difference in the long-term effects observed between patients with immediate postoperative pain relief and those with DR. While Barker et al evaluated the postoperative effects of patients mainly via subjective descriptions, in our study, postoperative effects were evaluated based on BNI pain scores. The patients obtained good curative effects, defined as postoperative BNI scores of I or II. This may be the reason why the results of this study are different from those reported in Barker et al Additionally, this study included patients who underwent only MVD as well as those who underwent PSR and MVD+PSR. Bigder et $\mathrm{al}^{7}$ found that the longterm effects of PSR were better in patients whose intraoperative exploration did not reveal the responsible vessels; in those patients, the postoperative BNI pain scores improved. One of the reasons for the differences in results between our study and those of Barker et al is that our study included patients who received PSR or MVD+PSR, while the study by Barker et al focused only on patients who received MVD.

To date, there is no clear time point for the occurrence of $\mathrm{DR}$, and there is therefore a great deal of controversy regarding when to perform a reoperation in patients who experience postoperative pain. Huang et $\mathrm{al}^{17}$ performed gamma knife surgery on $\mathrm{TN}$ patients who had no significant pain relief within 2 months after MVD. However, Xu et al ${ }^{18}$ evaluated TN patients who had unrelieved pain after MVD for at least 1 year before they underwent percutaneous balloon compression. Based on the results of this study, we do not recommend that TN patients who do not experience immediate pain relief after MVD and/or PSR should undergo immediate reoperation. Our study found that the average duration of postoperative pain observed in patients with DR was 3 months; therefore, we suggest that patients with no immediate postoperative pain relief should be observed for at least 3 months before reoperation. The time required to evaluate the ineffectiveness of surgical treatment should also be defined as at least 3 months after surgery.

\section{Limitations}

This study had the following limitations. First, this study was a retrospective study. Due to the long follow-up period, patients may have had unclear memories, and this may have led to bias and potential data loss. The missing data may also have caused bias. Second, the sample size of this study was small. We hope to carry out a more detailed study with a larger sample size in the future. Finally, this study targeted only patients with primary $\mathrm{TN}$, and the results of this study are therefore not applicable to patients with secondary $\mathrm{TN}$ or those with other neurological diseases. 


\section{Conclusion}

In our study, the incidence of postoperative DR was $19 \%$ in TN patients who underwent microneurosurgery with a retrosigmoid approach. The average duration of DR was approximately 3 months, and the occurrence of DR did not affect long-term outcomes. Although univariate analysis found a certain correlation between double-artery compression and the occurrence of DR, multivariate analysis found no correlation between any factor and the occurrence of DR. Our study results suggest that the time at which operative failure is defined should be at least 3 months after surgery.

\section{Disclosure}

The authors report no conflicts of interest in this work.

\section{References}

1. Nunta-Aree S, Patiwech K, Sitthinamsuwan B. Microvascular decompression for treatment of trigeminal neuralgia: factors that predict complete pain relief and study of efficacy and safety in older patients. World Neurosurg. 2018;110:e979-e988. doi:10.1016/j.wneu.2017.11.147

2. Cruccu G, Finnerup NB, Jensen TS, et al. Trigeminal neuralgia: new classification and diagnostic grading for practice and research. Neurology. 2016;87(2):220-228. doi:10.1212/WNL.0000000000002840

3. Maarbjerg S, Di Stefano G, Bendtsen L, Cruccu G. Trigeminal neuralgia - diagnosis and treatment. Cephalalgia. 2017;37(7):648-657. doi: $10.1177 / 0333102416687280$

4. Cruccu G, Gronseth G, Alksne J, et al. AAN-EFNS guidelines on trigeminal neuralgia management. Eur J Neurol. 2008;15(10):10131028. doi:10.1111/j.1468-1331.2008.02185.x

5. Patel SK, Liu JK. Overview and history of trigeminal neuralgia. Neurosurg Clin North Am. 2016;27(3):265-276. doi:10.1016/j.nec.2016.02.002

6. Jafree DJ, Williams AC, Zakrzewska JM. Impact of pain and postoperative complications on patient-reported outcome measures 5 years after microvascular decompression or partial sensory rhizotomy for trigeminal neuralgia. Acta Neurochir (Wien). 2018;160(1):125-134. doi:10.1007/s00701-017-3350-6

7. Bigder MG, Krishnan S, Cook EF, Kaufmann AM. Microsurgical rhizotomy for trigeminal neuralgia in MS patients: technique, patient satisfaction, and clinical outcomes. J Neurosurg. 2018;1-12.
8. Brinzeu A, Drogba L, Sindou M. Reliability of MRI for predicting characteristics of neurovascular conflicts in trigeminal neuralgia: implications for surgical decision making. J Neurosurg. 2018;1-11.

9. Wu A, Doshi T, Hung A, et al. Immediate and long-term outcomes of microvascular decompression for mixed trigeminal neuralgia. World Neurosurg. 2018;117:e300-e307. doi:10.1016/j.wneu.20 18.06.016

10. Inoue T, Hirai H, Shima A, Suzuki F, Fukushima T, Matsuda M. Diagnosis and management for trigeminal neuralgia caused solely by venous compression. Acta Neurochir (Wien). 2017;159(4):681-688. doi:10.1007/s00701-017-3085-4

11. Feng BH, Wang XH, Li ST. Posterior fossa re-exploration for recurrent trigeminal neuralgia: operative findings and surgical techniques. J Craniofac Surg. 2018;29(5):1284-1286. doi:10.1097/SCS.000000 0000004576

12. Gu W, Zhao W. Microvascular decompression for recurrent trigeminal neuralgia. J Clin Neurosci. 2014;21(9):1549-1553. doi:10.1016/ j.jocn.2013.11.042

13. Rogers CL, Shetter AG, Fiedler JA, Smith KA, Han PP, Speiser BL. Gamma knife radiosurgery for trigeminal neuralgia: the initial experience of The Barrow Neurological Institute. Int $J$ Radiat Oncol Biol Phys. 2000;47(4):1013-1019. doi:10.1016/s0360-3016 (00)00513-7

14. Sindou M, Leston J, Decullier E, Chapuis F. Microvascular decompression for primary trigeminal neuralgia: long-term effectiveness and prognostic factors in a series of 362 consecutive patients with clear-cut neurovascular conflicts who underwent pure decompression. J Neurosurg. 2007;107(6):1144-1153. doi: $10.3171 /$ JNS-07/12/1144

15. Barker FG 2nd, Jannetta PJ, Bissonette DJ, Larkins MV, Jho HD. The long-term outcome of microvascular decompression for trigeminal neuralgia. $N$ Engl J Med. 1996;334(17):1077-1083. doi:10.1056/ NEJM199604253341701

16. Bick SK, Huie D, Sneh G, Eskandar EN. Older patients have better pain outcomes following microvascular decompression for trigeminal neuralgia. Neurosurgery. 2019;84(1):116-122. doi:10.1093/neuros/ nyy011

17. Huang CF, Chiou SY, Wu MF, Tu HT, Liu WS. Gamma Knife surgery for recurrent or residual trigeminal neuralgia after a failed initial procedure. J Neurosurg. 2010;113 Suppl:172-177. doi:10.31 71/2010.8.GKS10915

18. Xu W, Jiang C, Yu C, Liang W. Percutaneous balloon compression for persistent or recurrent trigeminal neuralgia after microvascular decompression: personal experience of 28 patients. Acta Neurol Belg. 2018;118(4):561-566. doi:10.1007/s13760-0170858-8
Journal of Pain Research

\section{Publish your work in this journal}

The Journal of Pain Research is an international, peer reviewed, open access, online journal that welcomes laboratory and clinical findings in the fields of pain research and the prevention and management of pain. Original research, reviews, symposium reports, hypothesis formation and commentaries are all considered for publication. The manuscript management system is completely online and includes a very quick and fair peer-review system, which is all easy to use. Visit http:// www.dovepress.com/testimonials.php to read real quotes from published authors. 